\title{
O passado inabordável e a necessidade de imaginação: Tabu, de Miguel Gomes
}

\author{
Mariana Duccini Junqueira \\ da Silva \\ Doutora em Ciências da Comunicação \\ pela Escola de Comunicação e Artes da \\ Universidade de São Paulo. Professora \\ do Insper Instituto de Ensino e Pesquisa. \\ E-mail: marianaduccini@gmail.com
}

Resumo: Tabu (2012), filme do realizador português Miguel Gomes, assume expressividade artística pela articulação de um enredo tecido por fragmentos de narrativas memorialísticas, em que esse arranjo se torna o principal aspecto constituinte da obra. A esse respeito, sobrevém ainda uma disposição ficcional, como gênero narrativo, que conforma a realização. Certa "romantização" de eventos históricos específicos, cremos, potencializa em nosso objeto a expressão da dinâmica memorialística: o retorno ao tempo perdido, a um outrora mítico, é uma empreitada impossível por natureza, inextricável de arranjos narrativos, ainda quando tratar de episódios que tiveram lugar na realidade.

Palavras-chave: Tabu; Memória; Ficção; História; Colonialismo português.

Title: The unapproachable past and the need for imagination: Tabu, by Miguel Gomes

Abstract: Portuguese director Miguel Gomes's movie Tabu (2012) acquires artistic expressivity through a plot woven by fragments of reminiscent narratives, which become the main aspect of the film. In this regard, a fictional disposition ensues as a narrative genre, which conforms the performance. We believe that, in this subject, a certain "romanticizing" of specific historical events enhances the expression of the reminiscing dynamics: the return to a lost time, a mythical past, is an impossible task by nature, inextricable from narrative procedures, even when it evokes episodes that took place in reality.

Keywords: Tabu; Memory; Fiction; History; Portuguese colonialism. 


\begin{abstract}
Pelo menos, se me fosse concedido tempo suficiente para terminar a minha obra, não deixaria eu, primeiro, de nela descrever os homens, o que os faria se assemelharem a criaturas monstruosas, como se ocupassem um lugar tão considerável, ao lado daquele tão restrito que lhes é reservado no espaço, um lugar, ao contrário, prolongado sem medida - visto que atingem simultaneamente, como gigantes mergulhados nos anos, épocas tão distantes vividas por eles, entre os quais tantos dias vieram se colocar - no Tempo ( $E m$ busca do tempo perdido, Proust).
\end{abstract}

A inscrição da vida dos homens em um Tempo que se prolonga indefinidamente, conforme a aventura literária de Proust, não se perfaz senão como um arranjo específico de experiências memorialísticas que, em um presente enunciativo, precipitam-se na forma de uma narrativa. O presente é, assim, o tempo por excelência da memória: a única maneira de se contemplar o tempo perdido é incrustá-lo em um momento atual, eivando-o de sentidos que dão compleição às próprias experiências dos sujeitos. Se no passado sempre resta algo de inabordável (SARLO, 2007), é porque o esquecimento é a força constitutiva da memória, aquilo que a obriga à reelaboração do outrora vivido.

Uma recordação surge ao espírito sob a forma de uma imagem que, espontaneamente, se dá como signo de qualquer coisa diferente, realmente ausente, mas que consideramos como tendo existido no passado [...]. O passado está, por assim dizer, presente na imagem como signo da sua ausência, mas trata-se de uma ausência que, não estando mais, é tida como tendo estado. (RICOEUR, 2003).

${ }^{1}$ Ricoeur (2003) alude ao estabelecimento da história cultural nos termos de uma reordenação do estatuto da memória, que passa, então, de matriz da história a objeto da história; trata-se da inserção dessa disciplina no âmbito de outros fenômenos culturais encarados como representações.

\footnotetext{
${ }^{2}$ Essa estruturação é bastante própria à obra cinematográfica de longametragem de Gomes, como atestam os filmes anteriores: A cara que mereces (2004), em que a dualidade se perfaz em termos metalinguísticos (um filme que se engendra dentro do próprio filme), e Aquele querido mês de agosto (2008), em que o contraste se faz entre o regime ficcional e o regime documental.
}

Em um esforço para reencontrar aquilo que só se materializa nos termos de uma ausência, o trabalho de memória (ou, mais especificamente, de rememoração) tem de se haver com as lacunas próprias a toda ordenação narrativa, sempre da ordem da organização e da seleção. Se o acontecimento se instala situadamente no tempo, é como relato que se reveste de uma possibilidade, ainda que precária, de permanência. É assim que o próprio sentido da história tem a memória como um de seus objetos privilegiados ${ }^{1}$, contemplando o esquecimento constitutivo como força motriz para a ressignificação de eventos historicamente estabelecidos. Sobre o velho vigora, então, o novo, o inédito possível. Por outras palavras, a construção dos sentidos não é outra coisa que a revisitação - e frequentemente o deslocamento de versões já bem assentadas em um repertório coletivo: existe nessa dinâmica um "saber discursivo que faz com que, ao falarmos, nossas palavras façam sentido. [A memória] se constitui pelo já-dito que possibilita todo dizer" (ORLANDI, 2007, p. 64).

Tabu (2012), filme do realizador português Miguel Gomes, assume expressividade artística pela articulação de um enredo ficcional totalmente tecido por fragmentos de narrativas memorialísticas, em que esse arranjo se torna o principal aspecto constituinte da obra. De maneira mais abrangente, porque o dado histórico retorcido por uma operação de memória aparece como marca de um posicionamento enunciativo. Aqui, coexistem tanto a rememoração de um episódio sócio-político capital da história portuguesa (o processo de neocolonialismo empreendido em terras africanas nos anos 1950-1960) quanto a própria memória do cinema como instituição cultural (em alusão ao período clássico de Hollywood, sobretudo a partir dos anos 1930). De maneira mais situada, porque a diegese fílmica traz as categorias de tempo, espaço e personagens imbricadas a uma estrutura narrativa díptica ${ }^{2}$, que enlaça o presente e o passado, o aqui e o alhures, a velhice e a juventude - dualidades dispostas em correspondência com as duas porções temáticas (à parte um breve prólogo) em que o filme se divide: "Paraíso perdido" e "Paraíso".

Nosso intento analítico, entretanto, não se orienta aqui pelo "desembaraçamento" dos feixes de memória que sustentam o enredo fílmico (por um lado, aqueles que 
se situam macroestruturalmente, em termos de processos da história portuguesa e da história do cinema, que a seu modo se inscreveram na realidade social; por outro, aqueles mais circunscritos, componentes da tessitura episódica de Tabu, em que o exercício ficcional de rememoração pelos personagens reelabora os dramas existenciais que vivenciaram). Trata-se, ao contrário, de percorrer as estratégias pelas quais a obra, em chave poética, celebra o amplo domínio da memória, imiscuindo na "grande história" os episódios particulares.

A esse respeito, sobrevém ainda a referida disposição ficcional, como gênero narrativo, que conforma a realização. Certa "romantização" de eventos históricos específicos, cremos, potencializa em nosso objeto a expressão máxima da dinâmica memorialística: o retorno ao "tempo perdido", a um outrora mítico, é uma empreitada falha por natureza, inextricável de um arranjo narrativo, mesmo quando tratar de episódios que tiveram lugar na realidade.

Isso porque não se reencontra o tempo perdido senão por meio de artifícios de lembrança, eles próprios lacunares. Se nenhum evento pode ser reconstituído em sua totalidade (suas temporalidades múltiplas, seus ditos e interditos, suas certezas e suas esquivas), é entretanto sob a ordem das ficções - e somente assim - que as vivências podem ser significadas e comunicadas. Por ficção, em sentido amplo, entendemos as operações que tornam inteligível uma "ordem do mundo", um trabalho de construção que distribui os modos pelos quais os sujeitos tomam parte em um universo sensível comum (RANCIÈRE, 2005), têm suas experiências compreendidas e valoradas.

No filme de Gomes, a modulação patentemente ficcional (em contraste com uma disposição documentarizante, ainda que certo grau de ambivalência possa ser depreendido em $\mathrm{Tabu}^{3}$ ) confere autossuficiência à narrativa, que se torna tanto

${ }^{3}$ Quanto a essa questão, já referimos a presença, em Tabu, de aspectos históricos concretos do processo neocolonialista português na África e da alusão em paráfrase estética a períodos específicos do cinema industrial. Secundariamente, é possível considerar o fato de que a segunda parte do filme ("Paraíso") conta com uma narração em voz over, tão comumente associada à forma documentária, mas que se presta, na obra, à diegese ficcional: o narrador tem o sintomático nome de Gianluca Ventura, personagem que, na velhice, rememora as aventuras e desventuras da juventude, dando coesão às duas partes em que o filme se divide. Lembremos ainda que a referida segunda parte de Tabu foi prioritariamente realizada sob o improviso por parte dos atores e da equipe técnica, visto que as restrições orçamentárias inviabilizavam a observância ao roteiro, como refere Miguel Gomes em entrevista a Heitor Augusto. mais complexa na medida de sua ordenação por flashbacks que vão desvendando o enigma da "queda": a passagem do paraíso ao paraíso perdido, que, no filme, é disposta em ordem inversa. Há assim, no interior da unidade ficcional do enredo, uma espécie de gradiência da fantasia e da fabulação, partindo-se de um presente sem atrativos rumo a um passado mágico que se esvaiu.

A primeira parte, "Paraíso perdido", traz à cena o momento contemporâneo, marcado pelo vazio existencial de Pilar (Teresa Madruga) e pelos delírios senis de Aurora (Laura Soveral). A segunda parte, "Paraíso", estrutura-se por meio da narração memorialística de Gianluca Ventura (Henrique Espírito Santo), que remete o espectador a um algures fausto e exótico, quando as vicissitudes da juventude e da inocência - dele e de Aurora - precipitam a ruína, tornando inteligível ao espectador o sentido de renúncia e de decadência que obseda o presente, preço a ser pago pela violação de um tabu.

\section{Do paraíso ao paraíso perdido: a expectativa que não se cumpre}

Logo de início, Tabu envolve a instância espectatorial em uma ambiência que remonta à estética dos filmes etnográficos clássicos, com a presença de um explorador europeu que, "no coração do continente negro", como sublinha a narração em voz over, desenvolve seu trabalho de pesquisa entre os nativos. Um efeito de objetivação da alteridade, nos termos da curiosidade e do exotismo, não deixa de perpassar essas cenas, em alusão a uma característica candente dos primeiros tempos da antropologia visual. Ao mesmo turno, um adensamento subjetivo invade as imagens, mas não se refere às "singularidades do outro", senão ao pathos do próprio explorador. Por um confronto de pressuposições, a posição do investigador é desestabilizada, visto ser ele quem sucumbe a certa irracionalidade: atormentado pelas aparições do espírito da esposa, lançase à morte, devorado por um crocodilo. A voz over vem, então, relatar, após o episódio, a estranha presença naquelas terras longínquas de "um crocodilo triste, melancólico" que vive "acompanhado por uma dama d’outros tempos". 
À guisa de prólogo, essa curta sequência não integra organicamente a diegese de Tabu, ainda que anuncie articulações de sentido profícuas com a unidade da obra: trata-se antes de "um filme dentro do próprio filme", o que só se revela a posteriori, com a imagem da personagem Pilar em uma sala de cinema. Ora no centro do quadro, Pilar representa a espectadora modelar às ambições daquela primeira antropologia visual:

As sociedades descobertas pelo trabalho de exploração tornaram-se, nas imagens fotográficas e depois nas cinematográficas, suscetíveis de serem transportadas, divididas, montadas, referidas e sobretudo comentadas em relação a um lugar espectatorial cuja centralidade, característica essencial da referencialidade, não é posta em questão. (PIAULT, 2000, p. 9).

Assim interposto, entretanto, o plano da imagem de Pilar na sala de cinema desnaturaliza nossa própria fruição especular e instala a suspeita quanto a um espectador paradigmático: o que ele vê (ou ainda, o que vemos) não é o mundo em sua referencialidade, mas um arranjo de imagens e sons que dão compleição a um relato que aspira a ser "verdadeiro". O caráter contingente dessa verdade, natureza mesma de todo discurso (entre eles, o do cinema), se abisma como um dos efeitos expressivos em Tabu, seja pela disposição ficcional do filme, seja pelo exercício memorialístico dos personagens, que nos obriga ao cotejo entre temporalidades a fim de enlaçar as duas partes do enredo, seja ainda pelo manejo do recurso da intertextualidade pela instância enunciativa.

${ }^{4}$ Tabu, a story of south seas, obra de F. W. Murnau e R. Flaherty.
Quanto a este último aspecto, o próprio título do filme evoca a obra homônima ${ }^{4}$ de F. W. Murnau e R. Flaherty, em que o caráter exótico da paisagem da Polinésia Francesa é exaltado, servindo como pano de fundo à história de amor proibido entre os jovens Matahi e Reri, virgem sagrada que, tendo se tornado ela própria um "tabu", é impedida de viver o romance, mas foge com o rapaz - motivo pelo qual uma série de maldições se abate sobre eles. Também dividida em dois capítulos ("Paraíso" e "Paraíso perdido"), a obra de Murnau e Flaherty é uma das últimas produções do período do cinema silencioso nos Estados Unidos. Os pontos de conexão evidentes, no filme de Gomes, são ao mesmo tempo invertidos ou transfigurados, em um jogo de sentidos que, conforme referimos, repõe a tradição e a desloca, volta ao primado do mesmo para enunciar o novo.

A ordenação díptica da narrativa no Tabu de 1931 vai da causa ao efeito (ou do paraíso ao paraíso perdido), explicitando a punição como resultado da violação do interdito, que só pode ser expiada por uma renúncia (no caso, pela renúncia extrema: a morte de Matahi, o violador da interdição).

Também em díptico, mas com os "termos invertidos", o Tabu de 2012 configura o presente como o tempo por excelência da renúncia, das frustrações e da decadência, em uma Lisboa contemporânea. É apenas pelo tortuoso caminho da memória que se pode retornar ao paraíso, tempo em que as interdições não eram mais do que um conjunto de abstrações de ordem moral, insuficientes, entretanto, para refrear os ímpetos de uma juventude colonial que, na exuberância da África negra, dá forma a sonhos de poder, riqueza e sensualidade romântica.

"Paraíso perdido", então, tem como mote os temas da velhice e da solidão. Pilar, senhora de meia-idade, é o esteio de uma relação que se triangula com a vizinha Aurora e a empregada dela, Santa (Isabel Cardoso). A fim de preencher seus dias vazios, Pilar encarna a solicitude como principal marca identitária: desvela-se em cuidados em relação a Aurora, acometida pelas fragilidades físicas e mentais da senilidade. Engajada no ativismo político, Pilar não raro percebe as insuficiências de seu estar no mundo, e então reza, de forma quase "protocolar", por si e pelos seus (Aurora, em particular). Não há indícios de romance em sua vida, embora exista um pretendente, que tampouco a entusiasma. A juventude se esquiva 
da presença de Pilar, como é o caso da intercambista polonesa que dissimula não ser quem é para se livrar de sua companhia. Até mesmo a disponibilidade da personagem em ajudar é vista com desconfiança por Santa, que encara as incursões de Pilar na vida de Aurora como excesso de intromissão.

A empregada, aliás, representa um contraponto a Pilar nesse sentido. Cumpre seu dever e não se ocupa de cuidados suplementares em relação à patroa. Tornase simbólica na medida de sua origem: negra, advinda de uma das antigas colônias portuguesas (cuja referência não se literaliza), é acusada por Aurora de praticar "macumbas malditas" - alusão que se torna mais compreensível na segunda parte de Tabu, em que a jovem Aurora (Ana Moreira), herdeira de uma fazenda na África, convive de forma algo ambivalente com os rituais mágicos dos nativos. Frequentando uma escola para adultos, Santa mostra progressos nos estudos, o que a professora credita à leitura de Robinson Crusoe, romance setecentista de Daniel Defoe.

Assim como o herói do romance, visto por Watt (1997) como um dos mitos do individualismo moderno, Santa apresenta uma "sensibilidade conectada às coisas materiais", sabendo como "fazer uma acurada avaliação de resultados" (p. 162). Narrativa que celebra a tenacidade do indivíduo, em Robinson Crusoe a expressão do coletivo não tem lugar. Santa, representando toda uma geração de povos explorados que afluem à antiga metrópole em busca de uma vida melhor, não faz fé (por motivos óbvios) em empreendimentos coletivos. Metódica e trabalhadora, não alimenta pretensões que exorbitem seu horizonte cotidiano nem expressa emoções que ultrapassem a justa medida. Embora não se insurja contra os eventuais maus modos da patroa, também não destina a ela algum gesto de compaixão, como faz Pilar.

Aurora é a personagem mais enigmática dessa primeira parte de Tabu. Viciada em jogos de azar, perde dinheiro nos cassinos e relata sonhos que prometem bons augúrios, ao mesmo tempo em que reconhece a inutilidade deles em sua realidade insossa: "Sou uma tola, porque a vida das pessoas não é como nos sonhos". Suas formas de expressão são muitas vezes ricas de um simbolismo que, no entanto, parece resultar da caduquice. Pede a Pilar que reze por ela, pois "tem as mãos sujas de sangue". Apenas à beira da morte, essa condenação começa a fazer sentido, quando, já sem poder falar, Aurora desenha nas mãos de Santa o nome e a direção de um homem a quem Pilar deve procurar: Gianluca Ventura.

O tempo diegético do capítulo "Paraíso perdido" refere-se aos últimos dias de dezembro, período que sucede o Natal. Essa temporalidade específica, somada ao abandono de Pilar pela jovem intercambista e à decrepitude de Aurora, robustecem o sentido da solidão e do tédio. As sequências, em branco e preto, deslizam em movimentos lentos e diálogos intimistas. Na última noite do ano, Pilar vai ao cinema acompanhada do amigo-pretendente, que dorme enquanto ela chora com o filme a banda sonora com a música "Be my baby", das Ronettes, potencialmente remete a personagem à juventude e aos sonhos românticos de outrora, sentido que se amplifica quando a canção é retomada na segunda parte de Tabu, mas a essa altura identificada à história de amor entre Aurora e Gianluca ainda jovens, da qual Pilar também será uma espectadora, mas deslocada no tempo.

Nos delírios que antecedem sua morte, já ao final de "Paraíso perdido", Aurora pede à empregada Santa que "vá espreitar o crocodilo", porque ele adora "se meter em casa do senhor Ventura". Desse animal, o filme já dava indícios no prólogo.

Devorador do infeliz explorador que não encontra em vida alívio para o sofrimento amoroso, o crocodilo reaparecerá ainda em "Paraíso", o segundo capítulo. A figura do réptil é, assim, transversal à duração do filme - da mesma forma como pode ser considerada transversal ao próprio Tempo, posto que 
${ }^{5}$ Pensamos, mais uma vez, em como essa condição é trabalhada ironicamente quanto ao estatuto de que o crocodilo, simbolicamente, se reveste em Tabu. No prólogo, o narrador alude à tristeza e à melancolia do animal, evidentemente motivadas por uma espécie de "incorporação" do pathos de sua presa, o explorador europeu. A rigor, essa vontade de mimetização entre os humores do homem e os do animal não é nova. Um mito da antiguidade identifica um ruído específico emitido pelos crocodilos ao som dos soluços humanos. A própria expressão "lágrimas de crocodilo", que remete à condição de cinismo, reforça tal disposição.

${ }^{6}$ Por meio de informações extrafílmicas, sabemos que a segunda parte de Tabu foi rodada em Moçambique. No enredo, entretanto, não há menção clara à especificidade geográfica dessa colônia, o que potencializa um efeito de fábula.

${ }^{7}$ Embora todas as imagens do filme sejam em preto e branco, a diferença essencial está no uso da bitola de $35 \mathrm{~mm}$ para a primeira parte ("Paraíso perdido") e na de $16 \mathrm{~mm}$ para a segunda ("Paraíso"), neste caso com uma textura granulada que potencializa a atmosfera nostálgica, própria às reminiscências do personagem Gianluca Ventura.

${ }^{8}$ Apenas para efeito de eventual desambiguação, assumimos com Bordwell (2005) o período compreendido entre 1917 e 1960 quando nos referimos às representações e às estruturas da narrativa no cinema hollywoodiano clássico. essa forma de vida, cuja origem remonta a mais de 200 milhões de anos, chega aos dias atuais. No filme, o crocodilo metaforiza a permanência e, portanto, a condição de testemunha privilegiada das desventuras humanas. É, entretanto, uma articulação ostensivamente irônica em uma narrativa cuja chave é o domínio da memória: um crocodilo não pode efetivamente comunicar seu testemunho. Mas, sendo sua presença intransitiva o que perdura, explicita-se a condição frágil e perecível de todo trabalho de memória subjetiva: o verdadeiro triunfo é o da memória da natureza em sua incomunicabilidade, ao menos como se afigura ao nosso renitente antropocentrismo ${ }^{5}$.

Quando Pilar consegue encontrar Gianluca em um asilo, Aurora acaba de morrer. Após o enterro, ele, Pilar e Santa sentam-se em um café para rememorar a história da falecida, pelas palavras do outrora amante. "Ela tinha uma fazenda no sopé do monte Tabu" é a frase que incorpora a conexão entre as duas partes do filme.

Tal efeito de passagem e liame, materializado na fala de Gianluca, é contíguo a outra transição, esta de ordem imagética. $O$ ambiente do café tem uma expressividade kitsch, com plantas e aves decorativas que compõem uma bizarra floresta tropical. Mas é sob o comando da memória que esse cenário artificial "magicamente" se torna vivo, quando um plano-sequência finalmente nos imiscui em "Paraíso" - espaço-tempo mítico, embora em conexão com uma cronologia e uma geografia que identificam uma colônia africana sob o domínio português nos anos $1960^{6}$.

O recuo no tempo se inscreve tanto pela condução da narrativa com a voz over de Gianluca "velho" (contemporâneo), que relembra o passado, quanto por uma sensível modulação no registro das imagens ${ }^{7}$. A banda sonora se alterna entre a referida voz over do narrador, a música e alguns ruídos (estes dois últimos, diegéticos), mas diferentemente do que acontece no primeiro capítulo, os diálogos não são audíveis. Há uma clara remissão estético-narrativa ao cinema clássico industrial de Hollywood ${ }^{8}$, sobretudo em vista de dois aspectos: a combinação entre um segmento estilístico material e uma unidade dramatúrgica (o que motivava, nesse período, certa indiferenciação entre as noções de "plano" e "cena"); e a construção dos eventos segundo um princípio de causalidade, de forma que as configurações de tempo e espaço amalgamassem os efeitos de coerência e consistência (BORDWELL, 2005, p. 291-292).

Em conjunto, essas características mais evidentes conformam no interior da narrativa um lugar espectatorial que só pode se atualizar, ele mesmo, em termos do reconhecimento: é a própria memória de um cinema clássico que se erige, solicita correspondências, estimula formas de percepção e de inteligibilidade. Contiguamente, e de maneira talvez mais situada, é também a memória de toda uma geração colonial portuguesa que se mobiliza sob o signo da promessa de um futuro grandioso que, a exemplo do trágico amor entre Aurora e Ventura, não vinga.

\section{O sentido do tabu: sintoma da ambivalência}

Se "Paraíso perdido" é o capítulo marcado pelos signos da velhice, da solidão e das expectativas frustradas, é porque "Paraíso" compõe com ele uma dualidade reversa. $\mathrm{O}$ arco narrativo da segunda parte acompanha os anos faustos de Aurora, herdeira de uma fazenda na África, onde vive cercada por criados negros cuja única justificativa existencial é satisfazer-lhe os desejos. De arrebatadora beleza, a personagem tem o caráter modulado pela força. Cultiva comportamento e vestuário refinados, ao mesmo tempo em que vive em plenitude circundada pela vida selvagem (adepta da caça a animais de grande porte, é conhecida em toda a redondeza por uma pontaria infalível). O pai, que legou a ela a propriedade, os animais e os empregados, está morto - e o apreço da filha pelas caçadas é explicado como uma espécie de homenagem à memória dele. Ironicamente, 
a Aurora da velhice, que conhecemos em primeiro lugar ("Paraíso perdido"), manifesta outro aspecto herdado do caráter do pai: o vício dos jogos de azar.

O casamento conjuga Aurora a um marido (Ivo Müller) que faz fortuna com o plantio de chá na colônia - e partilha com a mulher uma existência despreocupada e feliz, também ele um entusiasta daquela vida exótica. O segundo capítulo de Tabu trabalha um imaginário mitológico que propulsiona os estereótipos eurocentristas sobre a vida dos nativos, mas essa proposição de leitura, claro está, se dá em chave crítica (recordemos sobretudo o papel simbólico de Santa, na primeira parte do filme, como detalharemos adiante).

Quando a gravidez sobrevém, Aurora pela primeira vez erra a pontaria e perde a presa durante uma caçada. Há qualquer coisa de premonitório nesse fato, conectado a uma previsão mágica de um dos empregados da fazenda, que costumava ler a sorte de seus senhores nas vísceras dos animais preparados para as refeições. $O$ cozinheiro antevê a gravidez da jovem, mas com a ressalva de que o futuro dela será desgraçado. Aurora, que até então condescendia com os rituais mágicos, acusa o empregado de heresia e o manda embora - o que ele anunciava, entretanto, era realmente a origem de sua ruína: ela havia se tornado um tabu, cuja violação não tardaria.

Sintoma de uma ambivalência emocional, um tabu deriva em interdições de origem remota e muitas vezes desconhecida, estendendo-se sobre uma coletividade na forma de sanções e castigos que frequentemente têm por princípio diversas modulações de banimento infligidas ao violador. Onde houver proibição, haverá por princípio lógico um desejo subjacente - donde a ambivalência constitutiva desse estatuto. Frequente mas não unicamente delimitada nas práticas sociais arcaicas, a característica extensiva de um tabu tem como correlata a noção de mana: espécie de poder mágico inerente a certos espíritos, indivíduos, animais, objetos ou mesmo estados que, creditado a uma origem sagrada, também pode, por contágio, suscitar o perigo, a conspurcação e a ruína daqueles que entrarem em contato com o portador do tabu (FREUD, 1999).

A presença magnética de Aurora, aliada à gravidez, é seu verdadeiro mana, o que arrebata o então rapaz Gianluca (Carlito Cotto), que chega àquelas terras como um forasteiro, graças a "desventuras que o fizeram deixar a casa paterna em Gênova", como refere o idoso Gianluca narrador. Na África, ele é acompanhado por Mário (Manuel Mesquita), amigo de boemia cuja ligação com a colônia remonta ao avô, que havia sido degredado muitos anos antes, quando as terras dominadas eram o destino penal àqueles que caíam em desgraça na metrópole.

Mário e Gianluca encarnam o ethos de "playboys" em um cenário pródigo e, sobretudo, livre. Esse ideário se torna especialmente pregnante a se ter em conta que, naquele período histórico, Portugal vivia sob o jugo do Estado Novo, quando a ditadura salazarista restringia duramente as liberdades coletivas e individuais. Sem lei nem rei, a África tropical revestia-se assim do estereótipo de paraíso reencontrado.

Não parece fortuito o fato de a figura paradigmática da autoridade - o pai-estar ausente da narrativa, cujo protagonismo é da juventude. O pai de Aurora já não vive; o de Gianluca rompera com o filho; de Mário, só temos remoto conhecimento do destino desonroso do avô. O próprio Mário, que acaba por ter um filho com uma das nativas, jamais assume essa responsabilidade e, eventualmente, como explica o narrador, fazia um "programa de domingo" com o menino - nas raras ocasiões em que se lembrava dele. O marido de Aurora é aquele que mais se aproxima da figura paterna, pelo fato de ter salvado a vida de Mário quando ele era ainda adolescente, o que estabeleceu um laço fraterno entre os dois.

$\mathrm{Na}$ companhia de outros colegas igualmente jovens, ricos e inconsequentes, as vidas desses personagens orbitam festas extravagantes, aventuras selvagens e 
sessões de tiro ao alvo que se tornam frequentes com os rumores de que os nativos estariam se armando para uma guerra colonial. Esses eventos são comumente embalados pelas canções da banda de Mário e Gianluca, que enlouquece as meninas. Mas é Aurora quem toma o coração do rapaz e, enquanto o filho cresce no ventre dela, os dois se envolvem em um romance secreto, de que somente Mário tem conhecimento - e se opõe, pelo respeito que nutre pelo marido de Aurora.

O romance tem início quando um filhote de crocodilo, que Aurora ganhara de presente do marido, vai se imiscuir na casa de Gianluca. $O$ amor dos dois é permeado pela simbologia da vida selvagem, dos instintos que não capitulam nem mesmo quando a barriga crescente de Aurora nua se interpõe entre ela e o amante durante o sexo. Uma breve separação dos dois, orquestrada por Mário, não resiste ao reencontro. Em adiantado estado de gravidez, Aurora foge na garupa da motocicleta de Gianluca. Rumam a uma aldeia nas proximidades, quando Mário os surpreende e entra em luta com o amigo. Aurora atira em Mário e imediatamente entra em trabalho de parto.

Assim implicado na desonra da amada e, indiretamente, na morte do melhor amigo, Gianluca tem remorsos, sentindo a visão da amada com a filha nos braços tão insuportável quanto a do cadáver do amigo. Com a chegada do marido de Aurora, assume-se como raptor dela e como assassino de Mário. Os amantes nunca mais se veem, apenas trocam cartas melancólicas, que minguam até cessarem de vez. Passam a viver, cada um, à sombra de seus crimes, mas o principal deles parece ter sido uma certa inocência, que dividem com toda a sua geração: a de não perceber que, a exemplo do paraíso perdido, a aventura colonial no "Ultramar" rebentaria em breve, como a própria barriga de Aurora, e só poderia resultar em sangue derramado. A morte de Mário serve, assim, de pretexto para a eclosão da guerra.

As palavras de Aurora em sua última correspondência a Gianluca são uma espécie de emblema do espírito do filme: "Se a memória dos homens é limitada, já a do mundo é eterna - e a ela ninguém poderá escapar. Peço que não revele em minha vida os monumentais crimes que vivemos". O crocodilo ressurge, então, no derradeiro plano de Tabu. Portador da memória do tempo, ele não pode, contudo, revelar os monumentais crimes dos homens, suas paixões, suas fraquezas, suas vitórias e derrotas tão situadas. Disso se incumbe o próprio cinema, mas este, na materialidade de sons e imagens que perenizam as histórias dos homens, só pode inscrever uma ausência: a de um tempo perdido, irrecuperável à mesma medida que é buscado.

\section{Conclusão}

Se a medida justa da violação de um tabu é frequentemente uma espécie de banimento, torna-se compreensível por que Aurora, na velhice, pode ser vista como uma exilada - e, não sem ironia, assim se converte justamente quando retorna à origem: a pátria portuguesa. Sem lugar próprio, o exilado é aquele que se perde de si e erra no tempo, tem de contornar uma fratura existencial para continuar vivendo.

A se considerar a dimensão sintomática dos tabus, é possível então relacionálo (o sintoma) não exatamente com os eventos potencialmente esquecidos (apartados do sujeito pela conformação de um trauma), mas com as "sobras" do acontecimento crucial, com aquilo que é latente e eventualmente irrompe na experiência ordinária do sujeito, sem que possa ser totalmente apagado (ZIZEK, 2003, p. 37).

É nessa dimensão que retomamos a ligação ambivalente entre Aurora e Santa, na primeira porção narrativa do filme. Nas emergências da violência verbal da 
patroa contra a empregada, resiste algo a mais que a patente dissimetria de forças própria a esse tipo de relação ou mesmo à antiga memória da relação metrópolecolônia, em termos de um vasto repertório de preconceitos. Santa é acusada por Aurora, sobretudo, de prática de bruxarias, o que só pode ser bem compreendido pelo cotejo com a segunda parte de Tabu. A "força mágica" que envolvia tudo o que dissesse respeito àquela vida na colônia recaiu sobre Aurora, causando sua ruína, fato que, no presente, Santa não a deixa esquecer. Mas os signos do tabu já eram literalmente visíveis no contexto do passado, como materializações naturais de uma advertência a que não se prestou atenção: o imponente monte de que se acercava a fazenda, não fortuitamente denominado Tabu; a barriga crescente de Aurora durante sua gestação; as vísceras do animal em que se adivinhava o destino da protagonista.

A inocência a que anteriormente aludimos como o mais sintomático dos crimes de Aurora e Gianluca refere-se especificamente a tal incapacidade de ver, marca de uma "identidade trágica do saber e do não-saber, da ação voluntária e do pathos sofrido" (RANCIÈRE, 2009, p. 23) -, análoga por certo àquela que obliterava a percepção quanto a um sistema colonial que gradualmente se esfacelava.

É também esse o "crime" que conduz diretamente ao paraíso perdido, tempo de um presente límbico. Se há aí, em relação ao trabalho dramatúrgico dos personagens, o imperativo moral do esquecimento, também há a nostalgia, bem expressa pelo sentido etimológico do termo: "dor do retorno". Essa ambivalência constitutiva pode ser pensada à luz da própria dinâmica da memória. Sempre há, no movimento de retorno, uma dor (ou mais extensivamente um pathos, algo que afeta o sujeito).

A lembrança não é o decalque de uma vivência pretérita, mas a precipitação de uma ausência, de um "isso foi", a ser significada no presente. O caráter conflituoso desse movimento inviabiliza o acesso imediato, literal, ao passado. Em Tabu, a opacidade é exacerbada: à reminiscência que se impõe, sobrevém a condição necessariamente oblíqua de toda rememoração. Para além de uma ordenação do enredo e da composição de personagens, essa estratégia se converte em marca autoral, já que reverbera na própria disposição enunciativa.

É assim que se enlaçam memórias que evocam realidades situadas no tempo e no espaço sociais, mas que, justamente por seu caráter de construto, deram forma a imaginários de toda uma época - e é nessa condição imaginária que continuam a ressoar e a significar em nosso cotidiano.

De parte a parte, o filme nos enreda nessas macronarrativas à medida que se desenvolve. Explicita o quanto nossas identidades são maleáveis, mas nunca indiferentes a todos esses repertórios que nos atravessam: a experiência como espectadores de cinema, leitores da história, cultores de maneiras e maneirismos próprios ao amor romantizado. Mas é acima de tudo nossa sina como seres de memória o que se faz sensível em Tabu: a mesma que, buscando obsessivamente a realidade de um passado inabordável, não tem como encontrar esse tempo senão materializando seus desejos de imaginação.

\section{Referências Bibliográficas}

BORDWELL, D. O cinema clássico hollywoodiano: normas e princípios narrativos. In: RAMOS, F. (org.) Teoria contemporânea do cinema - documentário e narratividade ficcional (vol. II). São Paulo: Senac São Paulo, 2005.

ENTREVISTA: Miguel Gomes. Revista Interlúdio. Disponível em: <http://www. revistainterludio.com.br/?p=5682>. Acesso em: 30 nov. 2015. 
FREUD, S. Totem e tabu. Rio de Janeiro: Imago Editora, 1999.

ORLANDI, E. P. Maio de 1968: os silêncios da memória. In: ACHARD, P. et al. Papel da memória. São Paulo: Pontes Editores, 2007.

PIAULT, M. H. Anthropologie et cinéma. Paris: Éditions Nathan/HER, 2000.

PROUST, M. O tempo recuperado. In: . Em busca do tempo perdido. Rio de Janeiro: Ediouro, 2004.

RANCIÈRE, J. A partilha do sensível. São Paulo: Editora 34, 2005.

. O inconsciente estético. São Paulo: Editora 34, 2009.

RICOEUR, P. Memória, história, esquecimento. Palestra realizada na Conferência Internacional Hauting Memories? History in Europe after authoritarianism. Budapeste: Publicações Universidade de Coimbra, 2003. Disponível em: <http:// www.uc.pt/fluc/lif/publicacoes/textos_disponiveis_online/pdf/memoria_ historia>. Acesso em 11 de nov. de 2015.

SARLO, B. Tempo passado - cultura da memória e guinada subjetiva. São Paulo: Companhia das Letras, 2007.

TABU. Direção: Miguel Gomes. Produção: Sandro Aguilar; Luís Urbano. Lisboa: O Som e a Fúria, 2012. (118 min.). son., color.

WATT, I. Mitos do individualismo moderno: Fausto, Dom Quixote, Dom Juan, Robinson Crusoe. Rio de Janeiro: Jorge Zahar, 1997.

ZIZEK, S. Bem-vindo ao deserto do real! São Paulo: Boitempo Editorial, 2003. 